\title{
Comportamento da umidade no solo por meio de sensores de resistência elétrica sob cobertura vegetal de eucalipto e de essências florestais nativas
}

\author{
Geberson Ricardo de Paula ${ }^{1}$ \\ Getulio Teixeira Batista ${ }^{1}$ \\ Marcelo dos Santos Targa ${ }^{1}$ \\ Claudinei Fonseca Souza ${ }^{1}$ \\ Nelson Wellausen Dias ${ }^{1}$ \\ Alan Miranda Ferreira dos Santos ${ }^{1}$ \\ ${ }^{1}$ Universidade de Taubaté - UNITAU
}

Estrada Mun. Dr. José Luiz Cembranelli, 5.000- 12080-010 - Taubaté - SP, Brasil

\{geberslp, gtbatista, targa.marcelo, claudinei.souza,nwdias, alanmnet\}@gmail.com

\begin{abstract}
This article presents the results of a study aimed at evaluating the behavior of water in the soil based on measurements of humidity in the soil profile. Soil humidity data were acquired in the period between June 16 and September 08, 2009, using a set of 96 Watermark $^{\mathrm{TM}}$ sensors installed at three soil depths, 20, 60, and 120 $\mathrm{cm}$ and in two plots. One plot (with 48 sensors) located in a four-year old Eucalyptus area and the other plot located in an adjacent native forest area. Both plots have the same slope and aspect characteristics. Soil physical and chemical characteristics were determined at the laboratory using collected samples. Results indicate that under Eucalyptus cover at the intermediate soil layer $(60 \mathrm{~cm})$ the humidity conditions is more stable. When precipitation occurs the top and intermediate layers respond more rapidly and the deeper layer requires more time to respond. Comparison between Eucalyptus and native forest cover indicate that forest cover had consistently higher water content in the soil at all three depth layers in this short term of observation.
\end{abstract}

Palavras-chave: vegetation, soil, humidity, sensor, vegetação, solo, umidade, sensores.

\section{Introdução}

O rebaixamento do lençol freático em diversas partes do mundo é uma realidade. A extração além da recarga natural de aqüíferos acontece hoje em todos os continentes, e, conseqüentemente abaixa os lençóis freáticos, como exemplo, a planície ao norte da China, responsável por $25 \%$ da safra chinesa de grãos, sofre a cada ano o rebaixamento de 1,5 metro no seu lençol freático (YANG E ZEHNDER, 2001).

O lençol freático na região do Vale do Paraíba está sendo rebaixado. A bacia de drenagem do rio Paraíba do Sul encontra-se na região com maior densidade populacional do Brasil, ou seja, o eixo São Paulo - Rio de Janeiro, e já apresenta sérios problemas de disponibilidade hídrica (ANA, 2003).

As plantas absorvem a água que está disponível no solo e práticas de manejo na agricultura visam promover condições ideais para o desenvolvimento das culturas. Por ser um reservatório aberto para a atmosfera e para os horizontes ou camadas mais profundas do perfil do solo, muitos pesquisadores têm procurado quantificar a capacidade de armazenamento desse reservatório (retenção de água), como também os fluxos que ocorrem tanto na superfície (infiltração e evaporação) quanto nas camadas mais profundas do solo (drenagem interna). Esses fluxos que ocorrem dentro do solo fazem parte de importantes processos do ciclo hidrológico. Findado o processo da infiltração, por exemplo, o movimento da água dentro do perfil do solo não cessa imediatamente e pode persistir por muito tempo. Esse movimento pós-infiltração é denominado drenagem interna ou redistribuição e se caracteriza por aumentar a umidade de camadas mais profundas pela água contida nas camadas 
superficiais inicialmente umedecidas (JURY et al., 1991). A infiltração de água no solo é influenciada pelo conteúdo inicial de água do solo, condutividade hidráulica e características da camada superficial do solo, além de ser afetada pela presença de camadas de baixa permeabilidade e duração da chuva ou irrigação (BERNARDO, 2002; CARLESSO e ZIMMERMANN, 2000). Inicialmente, seu valor é elevado, diminuindo com o tempo, até se tornar constante no momento em que o solo fica saturado. Assim sendo, sob chuva ou irrigação contínua, a taxa de infiltração se aproxima, gradualmente, de um valor mínimo e constante, conhecido por Velocidade de Infiltração Básica (VIB). Dados de VIB são imprescindíveis nos modelos utilizados para a descrição da infiltração de água no solo e dependem do selamento superficial provocado pelo impacto das gotas de chuva na superfície do solo.

\section{Objetivos}

Avaliar o comportamento da água no perfil do solo, no período de 16 de junho a 08 de setembro de 2009, por meio do monitoramento da umidade e da condutividade elétrica do solo em duas áreas pareadas (mesmo solo, mesmo face, mesma inclinação e próximas), uma plantada com eucalipto e outra coberta por essências florestais nativas.

\section{Metodologia}

O experimento está sendo conduzido na Fazenda Una, pertencente à Fibria, localizada na Estrada Municipal do Taboão, Bairro do Taboão, em Taubaté, São Paulo, Brasil, com coordenadas geográficas centradas em: latitude de $23^{0} 05^{\prime} 32^{\prime}$ S , longitude de $45^{0} 28^{\prime} 14^{\prime}$ W e altitude de $728 \mathrm{~m}$. Essa área da Fazenda Una foi cuidadosamente selecionada por possuir condições de solo, insolação, inclinação similares para as duas coberturas, em estudo: eucalipto e essências florestais nativas.

As análises físicas do solo (KIEHL, 1979), foram realizadas no Laboratório de Solos do Departamento de Ciências Agrárias da Universidade de Taubaté. O clima da região caracteriza-se por ser quente e úmido no verão e frio e seco no inverno (FISCH, 1995).

Os dados precipitação (P) foram coletados na Estação Meteorológica Automática A728, localizada no município de Taubaté, operada pelo Instituto Nacional de Meteorologia INMET que realiza observações horárias, desde 20 de dezembro de 2006 até os dias atuais. A estação está localizada nas coordenadas de $23^{\circ} 04^{\prime} 19^{\prime \prime}$ S e $45^{\circ} 53^{\prime} 02^{\prime \prime} \mathrm{W}$, em uma altitude de $571 \mathrm{~m}$.

Para verificar o comportamento da água foram utilizados os sensores Watermark, patenteados em 1985 e fabricados desde 1989 pela IRROMETER Company Inc. de Riverside, Califórnia (IRROMETER, 2003). Os sensores Watermark detectam a tensão de água no solo com base na resistência elétrica. De acordo com o fabricante, o sensor Watermark consiste de dois eletrodos concêntricos, inseridos em uma matriz de material especial, a qual é envolta e mantida no lugar por um chapa de aço inoxidável. O material da matriz foi selecionado para refletir ao máximo a mudança da resistência elétrica dentro da faixa correspondente à do crescimento das culturas agrícolas. Quando em operação, esta matriz está, constantemente, absorvendo ou perdendo a umidade para o solo. À medida que o solo seca, a tensão do sensor é reduzida e a resistência elétrica entre os dois eletrodos aumenta.

Um Medidor Digital Watermark foi utilizado para as leituras dos sensores. Segundo Tracom Imp. Exp. e Com Ltda. (2004), as principais características deste equipamento são:

- Leitura digital que varia de 0 kilo Pascal (totalmente úmido, i.e. imerso em água) e 200 kiloPascal (totalmente seco, seco ao ar, sem contato com água);

- Converte uma leitura de resistência elétrica do sensor em kilo Pascal de sucção;

- Preciso e estável; 
- Um único medidor lê todos os sensores instalados;

- Dimensão: 70 x 120 × 25 mm.

Para o monitoramento da tensão, em diferentes profundidades do solo, 96 sensores Watermark $^{\mathrm{TM}}$ foram instalados em um Latossolo Vermelho-Amarelo (EMBRAPA, 1999), sendo 48 sensores no solo com cobertura de Eucalipto (Figura 1) e o restante no solo com cobertura de Essências Florestais Nativas (Figura 2).

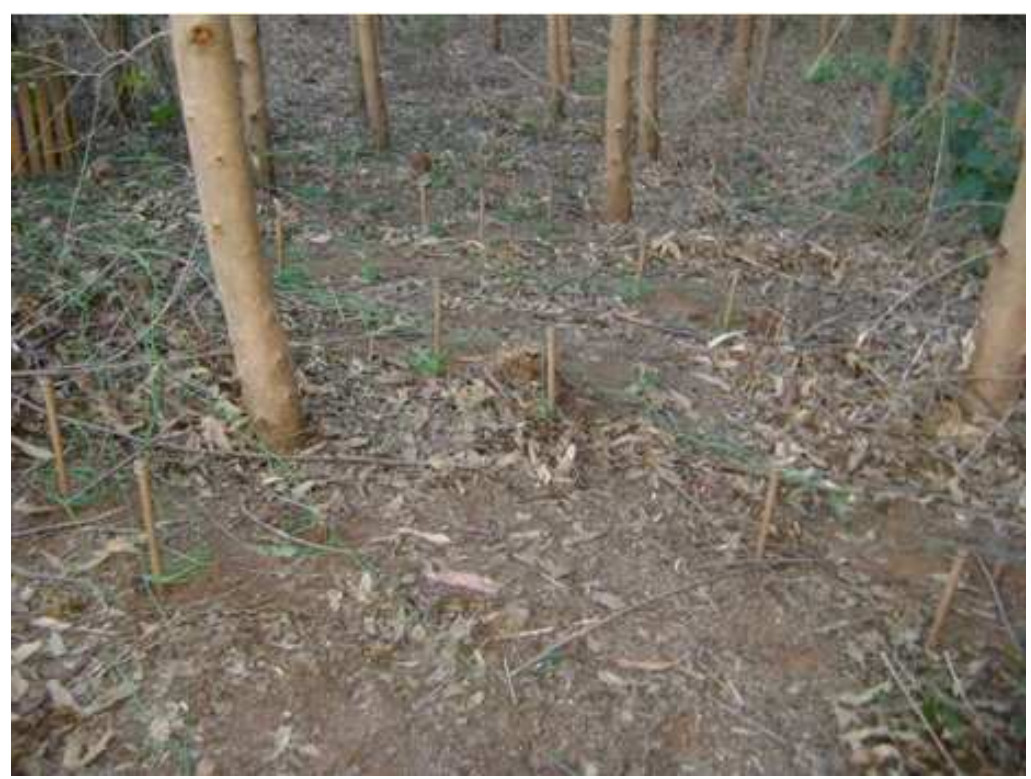

Figura 1: Detalhe da parcela de eucalipto mostrando os sensores Watermark instalados.

Os 48 sensores em cada área foram distribuídos em uma parcela e agrupados em conjuntos com três sensores nas profundidades de $20 \mathrm{~cm}, 60 \mathrm{~cm}$ e $120 \mathrm{~cm}$, que receberam a nomenclatura, sucessivamente A, B e C (Figura 3). Dessa forma, cada conjunto de sensores recebeu um número de 1 a 16 para a parcela no solo com cobertura de essências florestais nativas e de 17 a 32 para a parcela no solo com cobertura de eucalipto.

As medidas são realizadas semanalmente e analisadas com o auxílio de uma planilha eletrônica.

\section{Resultados e Discussão}

As características do solo com as coberturas de eucalipto e de essências florestais nativas para as profundidades de 20,60 e $120 \mathrm{~cm}$ encontram-se respectivamente nas Tabelas 1 e 2, onde se pode observar que o solo cultivado com eucalipto apresenta-se mais adensado e com menor porosidade total que o solo com cobertura de essências nativas. 


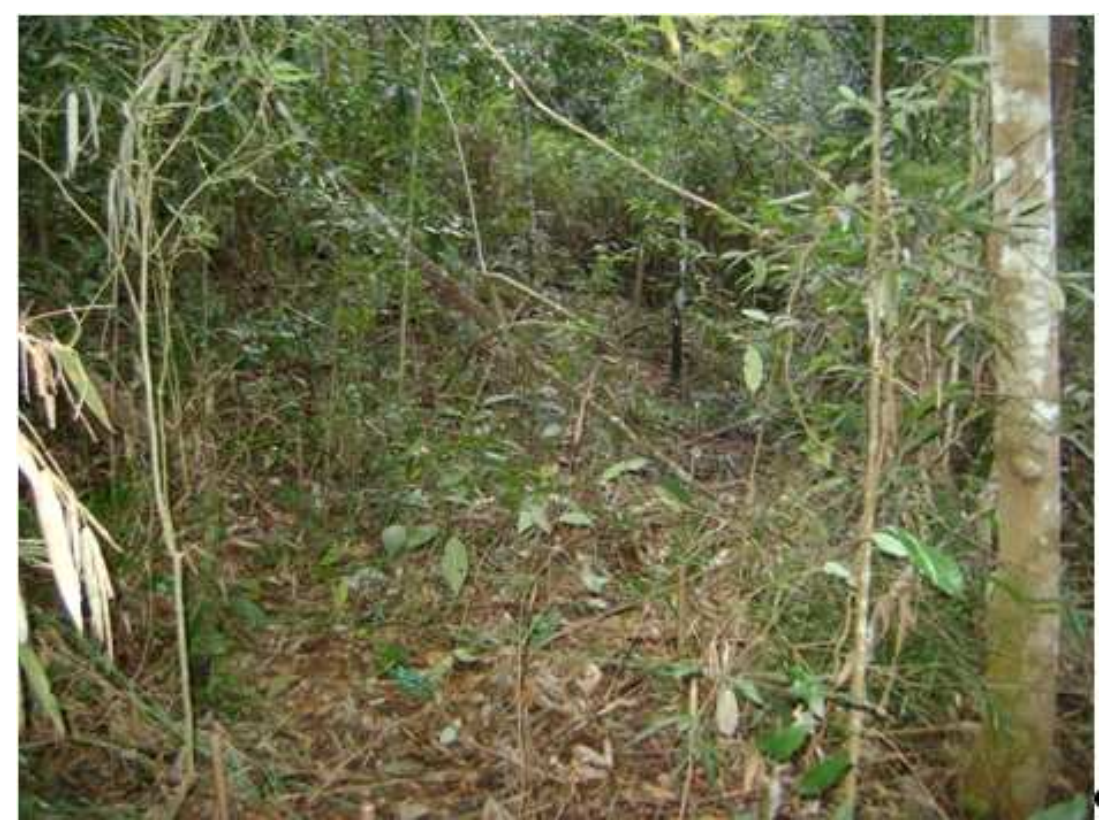

Figura 2: Detalhe da parcela de Essências Florestais Nativas mostrando os sensores Watermark instalados.

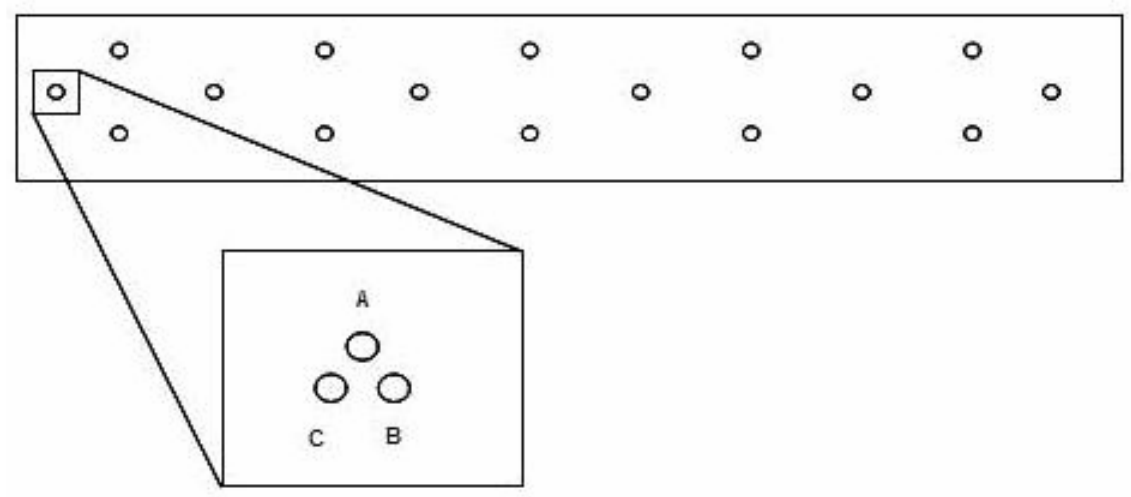

Figura 3: Modelo da parcela com a distribuição dos sensores no solo nas profundidades de $20 \mathrm{~cm}$ (A), $60 \mathrm{~cm}$ (B) e $120 \mathrm{~cm}$ (C).

Tabela 1. Características físicas do solo com cobertura de eucalipto.

\begin{tabular}{c|c|c|c|c}
\hline $\begin{array}{c}\text { Profundidades } \\
(\mathbf{c m})\end{array}$ & Classe Textural & $\begin{array}{c}\text { Densidade do solo - ds } \\
\left(\mathbf{g} / \mathbf{c m}^{\mathbf{3}}\right)\end{array}$ & $\begin{array}{c}\text { Densidade de partículas - } \\
\mathbf{d p} \\
\left(\mathbf{g} / \mathbf{c m}^{\mathbf{3}}\right)\end{array}$ & $\begin{array}{c}\text { Porosidade total - } \\
\mathbf{p} \\
\mathbf{( \% )}\end{array}$ \\
\hline 20 & Argila & 1,02 & 2,70 & 62,22 \\
60 & Argila & 1,24 & 2,77 & 55,23 \\
120 & Franco & 1,37 & 2,94 & 55,40 \\
\hline Média & & $\mathbf{1 , 2 1}$ & $\mathbf{2 , 8 0}$ & $\mathbf{5 6 , 7 9}$ \\
\hline
\end{tabular}

Tabela 2. Características físicas do solo com cobertura de essências florestais nativas.

\begin{tabular}{c|c|c|c|c}
\hline $\begin{array}{c}\text { Profundidades } \\
(\mathbf{c m})\end{array}$ & Classe Textural & $\begin{array}{c}\text { Densidade do solo - ds } \\
\left(\mathbf{g} / \mathbf{c m}^{\mathbf{3}}\right)\end{array}$ & $\begin{array}{c}\text { Densidade de partículas - } \\
\mathbf{d p} \\
\left(\mathbf{g} / \mathbf{c m}^{\mathbf{3}}\right)\end{array}$ & $\begin{array}{c}\text { Porosidade total - } \\
\mathbf{p} \\
\mathbf{( \% )}\end{array}$ \\
\hline 20 & Argila & 0,78 & 2,63 & 70,34 \\
60 & Argila & 1,04 & 2,66 & 60,90 \\
120 & Argila & 0,95 & 2,70 & 64.81 \\
\hline Média & & $\mathbf{0 , 9 2}$ & $\mathbf{2 , 6 6}$ & $\mathbf{6 5 . 4 1}$ \\
\hline
\end{tabular}


Na Tabela 3 encontram se os dados de precipitação acumulada semanalmente.

Tabela 3. Precipitação ( $\mathrm{mm})$ acumulada semanalmente no período de 16/06/2009 a 08/09/2009.

\begin{tabular}{c|c}
\hline Período & Precipitação (mm) \\
\hline $16 / 06 / 2009$ a 23/06/2009 & 0,0 \\
23/06/2009 a 30/06/2009 & 17,8 \\
30/06/2009 a 03/07/2009 & 0,0 \\
03/07/2009 a 13/07/2009 & 0,4 \\
$13 / 07 / 2009$ a 21/07/2009 & 0,6 \\
$21 / 07 / 2009$ a 28/07/2009 & 52,6 \\
$28 / 07 / 2009$ a 04/08/2009 & 13,0 \\
$04 / 08 / 2009$ a $11 / 08 / 2009$ & 0,0 \\
$11 / 08 / 2009$ a $19 / 08 / 2009$ & 9,4 \\
$19 / 08 / 2009$ a 26/08/2009 & 8,6 \\
$26 / 08 / 2009$ a $02 / 09 / 2009$ & 0,0 \\
$02 / 09 / 2009$ a 08/09/2009 & 22,8 \\
\hline
\end{tabular}

As medidas da tensão de água no solo (expressa em $\mathrm{kPa}$ ) que indicam a variação de umidade média, por meio dos sensores de resistência elétrica nas profundidades de $20 \mathrm{~cm}, 60$ $\mathrm{cm}$ e $120 \mathrm{~cm}$ em solo com cobertura de eucalipto e essências florestais nativas encontram-se na Tabela 4.

Tabela 4. Tensão de água no solo média $(\mathrm{kPa})$ medida com os sensores Watermark nas profundidades de $20 \mathrm{~cm}, 60$ e $120 \mathrm{~cm}$ no solo com cobertura de eucalipto e essências florestais nativas.

\begin{tabular}{c|c|c|c|c|c|c}
\hline \multirow{2}{*}{ Data } & \multicolumn{2}{|c|}{ Solo com cobertura de Eucalipto $(\mathbf{k P a})$} & \multicolumn{3}{|c}{ Solo com cobertura de Essências Nativas (kPa) } \\
\cline { 2 - 7 } & $\mathbf{2 0} \mathbf{~ c m}$ & $\mathbf{6 0} \mathbf{~ c m}$ & $\mathbf{1 2 0} \mathbf{~ c m}$ & $\mathbf{2 0} \mathbf{~ c m}$ & $\mathbf{6 0} \mathbf{~ c m}$ & $\mathbf{1 2 0} \mathbf{~ c m}$ \\
\hline $16 / 06 / 09$ & 0 & 0 & 0 & 0 & 0 & 0 \\
$23 / 06 / 09$ & 197 & 199 & 185 & 163 & 157 & 128 \\
$30 / 06 / 09$ & 143 & 74 & 150 & 27 & 39 & 106 \\
$03 / 07 / 09$ & 175 & 113 & 170 & 53 & 47 & 108 \\
$13 / 07 / 09$ & 152 & 121 & 162 & 43 & 63 & 104 \\
$21 / 07 / 09$ & 197 & 196 & 182 & 148 & 106 & 120 \\
$28 / 07 / 09$ & 105 & 95 & 135 & 12 & 44 & 105 \\
$04 / 08 / 09$ & 106 & 100 & 140 & 24 & 17 & 73 \\
$11 / 08 / 09$ & 166 & 177 & 166 & 103 & 36 & 66 \\
$19 / 08 / 09$ & 157 & 134 & 154 & 62 & 35 & 72 \\
$26 / 08 / 09$ & 133 & 144 & 147 & 15 & 36 & 90 \\
$02 / 09 / 09$ & 180 & 195 & 176 & 98 & 59 & 88 \\
$08 / 09 / 09$ & 130 & 99 & 143 & 21 & 21 & 81 \\
\hline
\end{tabular}

A Figura 4 apresenta os resultados da tensão de água no solo $(\mathrm{kPa})$ e a Precipitação $(\mathrm{mm})$ no solo com cobertura de eucalipto no período de 16/06/2009 a 08/09/2009, em diferentes profundidades. Pelos valores de tensão observa-se que na camada intermediária de $60 \mathrm{~cm}$ é a que mais se mantém estável e a camada mais profunda é a que permanece com a menor média de tensão. Quando ocorre a precipitação as camadas de $20 \mathrm{~cm} \mathrm{e} 60 \mathrm{~cm}$ respondem imediatamente, enquanto na profundidade de $120 \mathrm{~cm}$ é necessário um período maior para que a umidade e, consequentemente, a tensão se distribua. 


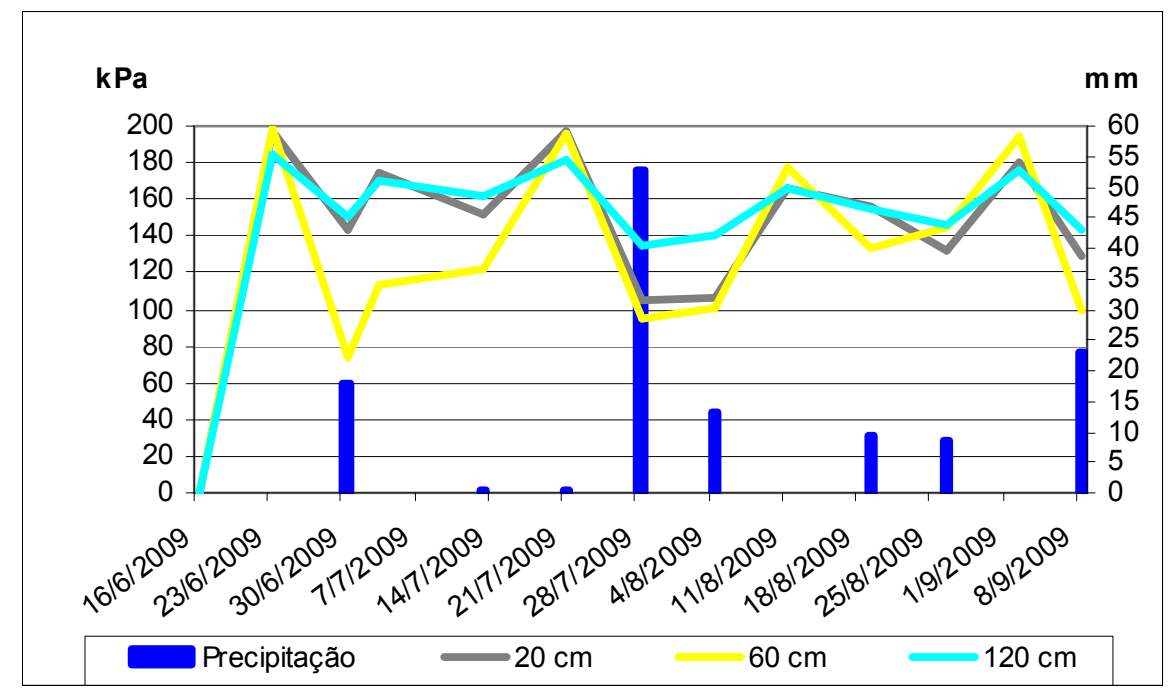

Figura 4: Tensão de água no solo $(\mathrm{kPa})$ e Precipitação Total $(\mathrm{mm})$ em solo com cobertura de Eucalipto.

A Figura 5 apresenta os resultados da tensão de água no solo $(\mathrm{kPa})$ e a Precipitação $(\mathrm{mm})$ no solo com cobertura de Essências Florestais Nativas no período de 16/06/2009 a 08/09/2009. Observa-se que a tensão nas camadas de $20 \mathrm{~cm}$ e $60 \mathrm{~cm}$ é maior. A camada de $120 \mathrm{~cm}$ no período se manteve com menor tensão.

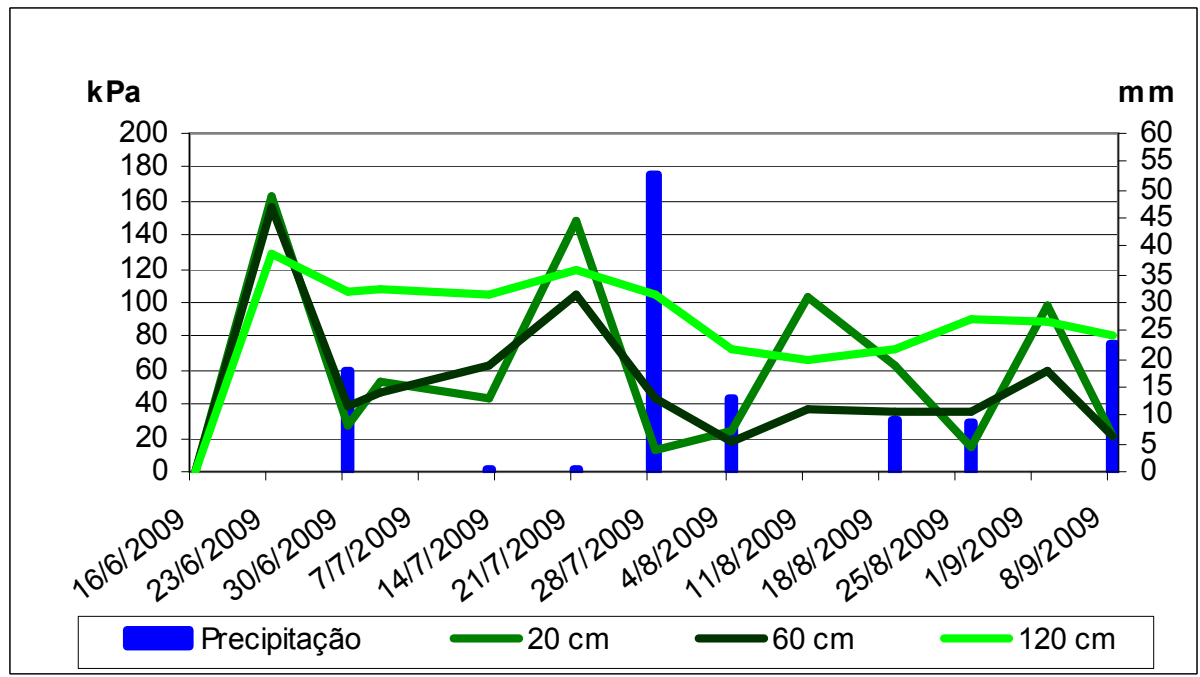

Figura 5: Tensão de água no solo $(\mathrm{kPa})$ e Precipitação Total $(\mathrm{mm})$ em solo com cobertura de Essências Florestais Nativas.

A Figura 6 apresenta a comparação da Tensão média em $(\mathrm{kPa})$ e a Precipitação $(\mathrm{mm})$ nas profundidades de $20 \mathrm{~cm}, 60 \mathrm{~cm}$ e $120 \mathrm{~cm}$ nos solos com cobertura de Essências Florestais Nativas e de Eucalipto. Observa- se que a tensão média no solo com cobertura de Essências Florestais Nativas é maior que a tensão média no solo com cobertura de Eucalipto. 


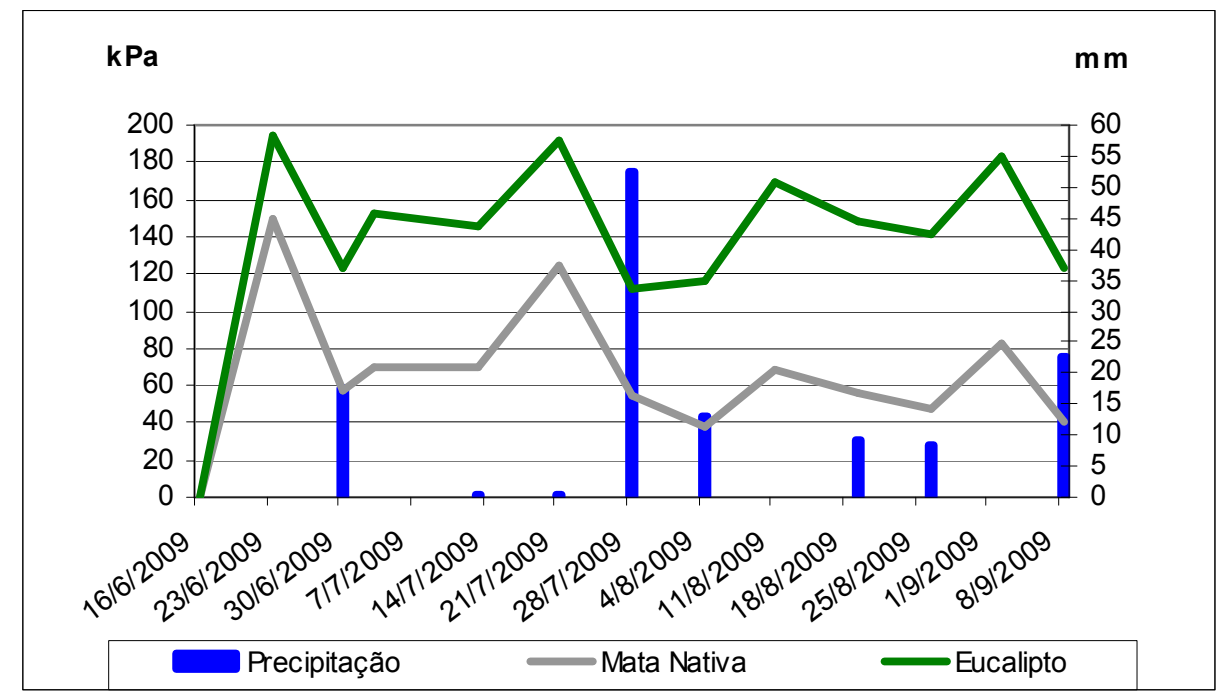

Figura 6: Tensão de água no solo $(\mathrm{kPa})$ e Precipitação Total $(\mathrm{mm}) \mathrm{em}$ solo com cobertura de Essências Florestais Nativas e de Eucalipto.

\section{Conclusões}

A partir dos dados encontrados e para as condições em que o trabalho foi realizado, chegou-se às seguintes conclusões:

Os sensores Watermark respondem bem às variações de umidade do solo, por meio da tensão, em função da evaporação, infiltração e precipitação.

De acordo com os resultados, a tensão média no solo com cobertura por Essências Florestais Nativas foi menor e o solo se manteve mais úmido por um período maior.

Como os dados levantados foram no período de baixa precipitação, espera-se que a análise da série completa, pela continuidade desse experimento, permita se chegar a uma conclusão sobre a tensão no solo no final de um ciclo anual completo e com isso se estimar a perda de água da silvicultura de eucalipto em comparação com a floresta de essências nativas nessa região.

\section{Referências}

ANA. Agência Nacional de Águas, 2003. Plano Nacional de Recursos Hídricos. Disponível em: $<$ www.ana.gov.br/pnrh>. Acesso em 29 de maio de 2009.

BERNARDO, S. Manual de Irrigação. 6 a Edição ver. Viçosa: UFV, 2002. 656p.

CARLESSO. R. e ZIMMERMANN, F. L. Água no solo: Parâmetros para o dimensionamento de sistemas de irrigação. Santa Maria: UFSM, 2000. 88p.

EMBRAPA. Centro Nacional de Pesquisas de Solos (Rio de Janeiro). Sistema Brasileiro de classificação de solos. Brasília: Embrapa Produção de Informação; Rio de Janeiro: Embrapa Solos, 1999. 412 p.

FISCH, G. Caracterização climática e balanço hídrico de Taubaté (SP). Revista Biociências, 1995. 1(1):81-90.

INSTITUTO NACIONAL DE METEOROLOGIA - INMET: Dados meteorológicos. Disponível em: < http: www.inmet.gov.br>. Acesso em junho, julho, agosto e setembro de 2009.

IRROMETER. Irrometer Soil Moisture Sensors. Disponível em: <http://www.irrometer.com/ sensors.html\#wm>. Acesso em: 01 de setembro 2009.

JURY, W. A.; GARDNER, W. R.; e GARDNER, W. H. Soil physics. 5.ed. New York, John Wiley \& Sons, 1991. 328p.

KIEHL, E. J. Manual de edafologia: relações solo-planta. São Paulo, Ceres, 1979. 264p. 
TRACOM IMP. EXP. E COM LTDA. Watermark. Disponível em: <http://www.tracom.com.br/Irrometer/pdf/ watermark.pdf>. 2004. Acesso em: 21 de maio 2009.

YANG, H.; ZEHNDER, A. J. B. China's regional water scarcity and implications for grain supply and trade. Environment and Planning, 33, 79-95. 2001. 